\title{
A sectoral approach allows an artful merger of climate and trade policy
}

\section{George David Banks ${ }^{1} \cdot$ Timothy Fitzgerald $^{2}$ (D)}

Received: 22 October 2019 / Accepted: 4 August 2020/Published online: 15 August 2020

(C) Springer Nature B.V. 2020

\begin{abstract}
Climate and trade policy present serious contemporary challenges for all nations. Developed market economies are struggling with trade policy in the modern era of globalization, and the resulting realignments are straining the post-war international economic order. National emissions pledges under the Paris Agreement appear at present to fall far short of achieving the greenhouse gas (GHG) emissions cuts that science suggests are needed to remain in a $<2{ }^{\circ} \mathrm{C}$ world. Merging climate and trade policy could provide developed economies a strategy for limiting global emissions while protecting and promoting their economic competitiveness. Since the adoption of the Kyoto Protocol, border carbon adjustments (BCAs) that would help protect domestic energy-intensive industry and prevent leakage have been discussed as a mechanism to make unilateral climate mitigation more politically attractive. Especially if implemented non-cooperatively, BCAs open the backdoor to protectionism and retaliation and potentially allow nations to retreat behind static barriers. Developments in international trade policy make this alternative to traditional climate diplomacy more viable today than previously and also increase the chance of climate protectionism. We propose an alternative policy framework - a cooperative sectoral tariff reduction (CSTR) - that would help provide dynamic incentives to improve performance, reduce the chance of BCAs being coopted for protectionist purposes, and create the foundation of a carbon club.
\end{abstract}

Keywords Border carbon adjustment · Cooperative sectoral tariff reduction · Climate policy · Trade policy

JEL codes $\mathrm{F} 18 \cdot \mathrm{Q} 54 \cdot \mathrm{Q} 56$

The current affiliation of Dr. George David Banks is House Select Climate Committee. The views expressed here are personal

Timothy Fitzgerald

timothy.fitzgerald@ttu.edu

1 Energy and Environment at the National Economic and National Security Councils, Washington, DC, USA

2 Rawls College of Business, Texas Tech University, Lubbock, TX 79409, USA 


\section{Introduction}

Developed market economies are struggling with trade policy in the modern era of globalization, with cracks showing in the post-war international economic order. Trade policy has been a recurring point of contention between the USA, European Union (EU), and China and has been especially salient since 2018. The rise of preferential trade agreements has usurped the multilateral approach to trade that bogged down, as best exemplified by the failed Doha Round. Preferential agreements have grown more expansive and now cover a broader scope of issues than historically.

At the same time, climate change presents an increasingly urgent political priority. Emissions reductions in early 2020 illustrate the potential economic cost of achieving reduction targets and underscore the magnitude of the policy challenge. The current round of national pledges under the Paris Agreement will fall far short of achieving the global greenhouse gas (GHG) emissions cuts that science suggests are needed to remain in a $<2{ }^{\circ} \mathrm{C}$ world. ${ }^{1}$ While progress was achieved at the Conference of Parties (COP) in Katowice on the rules for implementing national pledges (COP24 2019), there are a few expectations that parties to the Paris Agreement will table new contributions that cumulatively achieve peak emissions in the coming years. Moreover, this outlook is unlikely to improve as long as the world lags in the development and deployment of technologies that enable economic growth with significant decarbonization (IEA 2019).

Domestic policymaking continues to offer considerable flexibility in pursuing enforceable climate mitigation action. Paris Agreement pledges will spur continued and perhaps renewed efforts at the national and subnational levels, despite the global public good nature of reducing GHG emissions. Indeed, about $15 \%$ of the world's carbon emissions are already covered by various carbon pricing initiatives, suggesting that unilateral policies already have some traction despite competitiveness concerns (World Bank 2019).

Country-specific efforts to reduce GHG emissions face political constraints because first movers potentially face a competitive disadvantage in a global economy. While the competitive effects are estimated to be only about one-sixth of the total production decrease resulting from GHG constraints (Aldy and Pizer 2015), policymakers are loath to make decisions with potentially severe long-term output and employment consequences, even with compensating policy mechanisms like permit allocations that could offset some adverse effects. Furthermore, domestic climate mitigation targets can be undercut if multinational corporations shift production or supply chains offshore to avoid regulatory burdens, resulting in emissions leakage and job destruction (Copeland and Taylor 2004).

To address these two goals - preventing leakage and avoiding loss of competitiveness - a growing consensus has formed around using a tariff on embodied emissions in the form of a border carbon adjustment (BCA). A BCA is not the only possible tool that can be used to alleviate pressures from introducing or strengthening domestic carbon constraints but has emerged as the favored mechanism. Price-based interventions like tariffs are generally more

\footnotetext{
${ }^{1}$ See Climate Action Tracker at https:/climateactiontracker.org/. An anonymous referee rightly points out that one possible value of the Paris Agreement is aspirational and that subsequent national pledges may become more ambitious and set targets that would match scientific advice. The track record to date makes us less optimistic than others.
} 
economically efficient than standards (Fischer and Fox 2012). A wide variety of tax credits or other types of competitiveness policies could also be implemented to protect domestic firms but fail to gain the appeal of BCA for three reasons. Because industries that would need the largest tax credits may have insufficient tax liability to be made whole, the instrument might not be a viable alternative to tariffs (Gray and Metcalf 2017). Second, extensive systems of tax credits rewarding lower emissions intensity are likely to have unwelcome fiscal implications and therefore be infeasible. Third, these initiatives would potentially fall afoul of existing trade agreements and are generally less cost-effective than a price-based border adjustment like a BCA (Aldy 2017).

BCAs are not a new policy concept; they have been debated since the Kyoto Protocol to make unilateral climate mitigation more politically attractive (Cosbey et al. 2019). A considerable amount of academic theoretical work on BCAs has been summarized by Cosbey et al. (2019) and Kortum and Weisbach (2017). Without current national-level examples, BCAs are more theoretical than real, ${ }^{2}$ and so empirical analysis is lacking. Instead, analysis has largely relied on computable general equilibrium modeling (e.g., Balistreri et al. 2018). The vast majority of this simulation analysis has been focused on the creation of BCAs as a complement to unilateral domestic action to mitigate carbon emissions.

As a type of tariff, BCAs run counter to what has been the prevailing global economic order of trade liberalization, which until recently complicated serious discussion about adoption. A series of serious questions about how to implement BCAs within the framework of existing law have also dogged adoption, though a growing consensus is emerging about how these legal challenges can be successfully navigated (Mehling et al. 2019). Major implementation and monitoring questions remain, but BCAs are moving towards adoption and breathing life into more ambitious unilateral climate policy options.

Imposing BCAs also carries risks. If implemented non-cooperatively, they could allow "climate protectionism" (Holmes et al. 2011). Balistreri et al. (2019) draw on long-standing insights from trade theory to demonstrate that the policy choice is not as simple as setting a BCA equal to a domestic emissions charge, which introduces an important degree of discretion. Setting the tariff higher than necessary, particularly to gain support from domestic political interests, reinforces the protectionist concerns. Protectionist policies would reduce opportunities for developing nations to trade and grow wealthier. Designing around that inequity is also fraught. Excluding developing countries from a BCA would leave a loophole for leakage and reduce incentives for broader adoption of low-carbon technologies.

Given recent experience with trade retaliation, a unilateral BCA would likely meet retaliation. Helm et al. (2012) anticipated that this threat would actually turn into collaboration rather than retaliation. We are less optimistic that unilateral changes will have that effect, and the result could be a series of isolated and protectionist policies fracturing global trade. The spread of non-cooperative BCAs could have a similar effect on monitoring and verification standards. The end result would be a balkanized system that creates trade and investment barriers to lower-emissions goods.

Greater interest in increasing action on climate policy comes as American "tariff diplomacy" has opened Pandora's box and reset global norms about acceptable trade practices and the use of tariffs to achieve national objectives. While these efforts and associated legal challenges

\footnotetext{
${ }^{2}$ California has effectively imposed a subnational level BCA for electricity imports. This limited BCA provides an example but covers a single homogeneous product rather than the wide spectrum of goods traded internationally.
} 
have not yet resolved, it appears that imposing unilateral tariffs to address national security threats - which climate change undoubtedly is for many countries - will be both legal and acceptable going forward. BCAs are poised to fulfill the demand for more stringent carbon mitigation policies. Combined with the desire to curtail global emissions more quickly, exploring a climate and trade policy merger offers an opening to enhance harmonization of worldwide reporting standards.

\section{An alternative merger of climate and trade policy}

The confluence of climate and trade policy trends makes rollout of BCAs more likely. If implemented non-cooperatively, the outcome is potentially counterproductive by limiting trade, even in the greenest products. In today's window of opportunity, creating the proper incentives for favorable outcomes is crucial to the future success of climate and trade policy. An alternative is a cooperative sectoral tariff reduction (CSTR) approach to carbon adjustments, which has three characteristics to differentiate it from unilateral BCAs. First, it uses tariff reductions to create an incentive for good behavior-in this case, low carbon emissions - rather than just the punishment of a tariff. In this sense, the mechanism relies on carrots rather than just sticks. Second, the approach is sector by sector. It is true that some BCA proposals have anticipated sectoral rollout (von der Leyen 2019), as has been used in other unilateral climate policies including the EU Emissions Trading System. The CSTR is fundamentally different because it approaches each sector individually, creating a tournament structure within each industry and allowing the best performers to get the carrot of tariff reductions. Third, the system is cooperative on a plurilateral basis. Countries wanting to embrace trade as an opportunity rather than a source of carbon leakage could use a CSTR to achieve carbon mitigation goals with lower overall trade barriers. Such an agreement would help provide dynamic incentives to improve performance while reducing the chance that BCAs are used for protectionist motives.

A CSTR policy could help protect the economic gains from international markets, create a race-to-the-top competition in the "greening" of industries and supply chains, and significantly reduce GHG emissions. With agreement among participating countries, the tournament structure for tariff reductions would be open to all types of firms - private, public, and state owned. Energy-intensive and trade-exposed sectors that are responsible for a substantial share of global emissions are good candidates for such an approach, with reductions tailored to the structure of the industry. Each of the three characteristics of a CSTR is addressed in a greater detail.

\subsection{Tariff reductions}

A BCA creates a tariff based on carbon content of imports, so the same product is subject to a higher tariff as its carbon intensity increases. This naturally provides an advantage to greener products and penalizes the more carbon-intensive products. Differential tariffs could lead to price dispersion and less consumer change than might otherwise be expected, but the higher barrier should make trade in more carbon-intensive goods less attractive. The only outlet for products with high carbon intensity is in the domestic market if protected by a relatively high BCA.

The CSTR reduces the tariff rate for the cleanest products in each sector. This approach creates a virtuous tournament within major sectors, as firms try to earn the reward of discounted tariffs by demonstrating the lowest embodied emissions. The least emissions- 
intensive, or "green standard," products and producers would face a lower tariff (potentially zero) in those economies that participate in the system. The second-best company (or tier of firms) would face a slight adjustment, but less than third place and so forth, with the details potentially varying by sector. Consequently, each position in the emissions reduction tournament would hold a certain economic value, providing an incentive for companies that rank lower in the order to invest in reducing their carbon footprints to capture a higher-ranked position with reduced tariffs by all participating countries. This incentive system would hasten investments in cleaner technologies and business practices across the global supply chain. While the conventional BCA is intended to prevent emissions leakage, a CSTR seeks to promote negative leakage or an active mitigation of emissions by promoting trade in the greenest products.

To implement a CSTR, countries would not negotiate the standard for each industry. Instead, governments would agree on a process that generates industry standards objectively on a periodic basis, based on a set of agreed-upon inputs. The green standard for any given industry would be determined by an independent body that participating economies could establish or house in an existing international organization. Importantly, even in the case where a country does not have an explicit price on carbon emissions, that government could still participate in the CSTR if it recognized the green standard and accepted the required accounting standards that promote disclosure and transparency.

CSTR competition would raise standards for transparency and disclosure. Because applied tariff rates would depend on verified embodied emissions, it is imperative to have uniformity and agreement in reporting. Any BCA scheme faces a similar hurdle. Compared with the BCA, the CSTR approach holds greater promise for creating an incentive structure that allows competition across an industry and a "race to the top," regardless of country of origin. The reward of reduced tariffs would increase scrutiny of reporting and verification. A CSTR would lower the average applied tariff and avoid the degree of protectionism embodied in territorial BCAs that could punish both the cleanest manufacturers and producers based in foreign countries that may not have an equally robust national climate policy.

\subsection{Sectoral approach}

Approaching the problem sectorally provides two advantages. One is that by focusing on individual sectors, the costs of implementing the system could be lower by establishing a global standard for a sector rather than trying to merge different territorial systems across a range of products. Any system of BCAs faces similar monitoring and enforcement problems, though at a national level. These represent non-tariff barriers in addition to the tariff. Sectors may be better positioned to implement homogeneous monitoring practices due to similar production processes. Several new technologies are being deployed that make accounting less costly and more feasible to verify GHG emissions and increase confidence. While these currently verify quality characteristics in supply chains, they could be adapted to verify carbon intensity.

Setting the green standard would require monitoring of global supply chains, which is ambitious given varying governance capacities in the developing world. Individual industries would play an indispensable role in the development of a CSTR, as they have done in more successful international environmental negotiations (e.g., the Montreal Protocol). Governments would depend on their input on their own technical 
capacity in greening operations across supply chains, which would help determine the tariff reductions needed to promote innovation.

Second, there are substantial improvements to be made within sectors. There are significant heterogeneities in emissions intensity of output both between and within industries (Oda et al. 2012). As a result, the incidence of a first-best emissions charge would be very uneven, with potentially unpalatable political consequences. Output-based tax credits could be used to mitigate some of these concerns, though they may have unwelcome fiscal implications. Accordingly, an alternative approach may be needed. Previous work recognizes that environmental performance standards may provide similar incentives with fewer sectoral employment shifts (Hafstead and Williams 2018). None of these proposals provides an incentive for continual improvement and therefore poses a risk that addressing climate challenges with BCAs could lead to a retreat behind protectionist barriers.

A sectoral approach enables the CSTR to address whole supply chains and encourage multinational corporations to invest in greening their operations around the world. This also pushes the private sector to strengthen environmental compliance and enforcement regimes in countries that lack governance capacity.

\subsection{Cooperation and its possibilities}

Rather than implement BCAs unilaterally, under a CSTR policy, a group of likeminded economies could explore building an international regime that would provide dynamic incentives to improve performance. A group of participating economies would agree to construct their collective BCA to reward the relatively cleanest firms in each industry and promote continuing innovation. This would be a kind of carbon club (Nordhaus 2015), stepping in where multilateral efforts have thus far failed. The optimal size of such a coalition deserves further study, but building upon existing trade relationships will increase its size and the gains from cooperation.

Since 2018, the USA has disrupted global trade and climate policy. The trade disruption has been caused by unilateral imposition of import tariffs for a wide range of products, from energy-intensive commodities like steel and aluminum to technology and consumer products that generally have less embodied emissions. On the climate front, Congressional Republicans support the planned US withdrawal from the Paris Agreement because it fails to adequately limit global emissions. In both cases, the USA has reflected a willingness to disrupt a multilateral status quo in hopes of achieving more durable long-term gains when structural issues are addressed. While it may be a surprise to many observers, merging climate and trade policy offers an opportunity for improved cooperation between the EU and the USA.

At this time, the EU is poised to shape the future direction of the climate and trade regime. The European Commission is expected to introduce a proposal for a Carbon Border Adjustment Mechanism (CBAM) by the summer of 2021 as part of its European Green Deal (European Commission 2019). Prag (2020) documents additional proposals over time in Europe and the USA, but the EU is currently showing more initiative. The CSTR presents an opportunity for cooperation and collaboration.

Europeans are upset about US tariff diplomacy and disengagement from climate policymaking, which taken together appears to be shaping an emerging climate-trade agenda (Mehling et al. 2018). Yet, in its current efforts to expand climate policy into the trade domain, the EU, which is sensitive to perceptions that it is acting unilaterally, could use US and other OECD cooperation. Both the EU and the USA import more carbon than they export. Their 
multinationals are global leaders in climate action and innovation, clean procurement and supply chain management, and carbon disclosure. These factors suggest that the costs of verifying emissions embodied in products manufactured and sold around the world, including in developing countries, would be lower for their firms.

Other positive factors increase the possibility of greater consistency in transatlantic climate and trade cooperation. In the USA, enacting a BCA has gained notable support from democratic policy elites and right-leaning organizations that back a carbon tax (Biden (2020); Climate Leadership Council 2019). While the majority of American conservatives currently oppose a carbon regulatory regime that would politically necessitate a BCA, there is an increasing number of Republicans who argue that countries should purchase US goods because they are relatively cleaner from a GHG perspective. This creates an interesting prospect that Republicans could support a CSTR approach without an explicit federal carbon price. Accordingly, CSTRs could present an opportunity for improved collaboration between the EU and the USA - even under a Republican administration.

Initial collaborations would likely focus on energy-intensive industrial subsectors, but widely traded commodities with relatively simple supply chains are also good candidates: including fossil fuels, chemicals, and minerals. A CSTR covering fossil fuels and minerals, for example, would ensure that global demand for fossil fuels is met by the cleanest, most efficient production in terms of GHG life cycle, resulting in switching from relatively dirty to relatively clean fuels. Under a $<2{ }^{\circ} \mathrm{C}$ regulatory scenario, for example, a significant percentage of the world's fossil fuels should remain untouched without the commercialization of breakthrough decarbonization technologies (McGlade and Ekins 2015). A CSTR covering fossil fuels could create the right incentives to achieve this goal. Additionally, it would provide the USA, which is among the cleanest producers of fossil fuels from a GHG lifecycle perspective (Roman-White et al. 2019; Carnegie 2020), incentive to participate more consistently in international climate policy.

Cooperation can build on initial success by either adding additional sectors or by increasing the size of the coalition. Either would be a welcome extrapolation of success.

\section{Conclusion}

The odds of a merger of climate and trade policy are more likely than not in today's world of tariff diplomacy and a growing public demand for climate action. The free trade agenda has given way to the acceptance of using tariffs to achieve national interests, including threats to security. On the other hand, nationally determined contributions under the Paris Agreement currently fall far short of what is needed to maintain global temperatures at a safe level, requiring the introduction of non-traditional climate cooperation in international commerce and investment.

With multilateral efforts likely to fail to peak global GHG emissions any time soon, the merging of climate and trade policy offers greater flexibility in pursuing deeper, unilateral emissions cuts that are consistent with remaining in a $<2{ }^{\circ} \mathrm{C}$ world. The enactment of BCA measures would allow economies to undertake more ambitious domestic action while shielding their domestic producers from importers without similar carbon constraints.

Non-cooperative implementation of BCAs is likely to produce poor and potentially adverse policy outcomes, including an increase in protectionism and limited, inefficient opportunities 
to reduce global GHG emissions. Countries seeking to retreat behind walls of protectionism by imposing higher BCAs will suffer less global climate progress and greater isolation from gains from trade. Uncoordinated unilateral action could also harm multilateral efforts to harmonize emissions reporting by fostering multiple monitoring and verification systems, with long-term implications for linkage.

On the other hand, cooperative sectoral tariff reductions based on industry-established greenhouse gas benchmarks could create a "best-in-class" competition within major sectors, helping protect what remains of the free trade regime and "green" global supply chains. Importantly, CSTR competition would also cover state-owned enterprises, which would raise standards for transparency and disclosure. Multinational corporations that are dependent on overseas suppliers stand to benefit more from CSTRs than non-cooperative BCAs. All of these factors are favorable as the world explores policy options moving forward after coronavirus.

While BCA and CSTR implementation does not require domestic carbon constraints (prices, quantities, or standards) to go into effect, they are likely to be paired with domestic policymaking in the countries that adopt the approach. Manufacturers in countries that participate in the system, including their supply chains, can be expected to advocate for improved environmental governance and cleaner energy policies, including increased government expenditures in research and development, to help lock in longer-term competitive advantages in the global market. Thus, multinationals with operations in developing economies would play a more active role in helping supplement or assist in the development of host government environmental enforcement and compliance. Certainly, the politics of the CSTR would introduce a new dynamic in climate change policymaking as efforts to degrade environmental policy would likely meet resistance from manufacturers sensitive to related negative impacts on trade.

Acknowledgments The authors would like to thank Detlef van Vuuren and two anonymous referees for their detailed comments on this manuscript.

\section{References}

Aldy JE (2017) Frameworks for evaluating policy approaches to address the competitiveness concerns of mitigating greenhouse gas emissions. Natl Tax J 70(2):395-420

Aldy JE, Pizer WA (2015) The competitiveness impacts of climate change mitigation policies. J Assoc Environ Resour Econ 2(4):565-595

Balistreri EJ, Böhringer C, Rutherford TF (2018) Carbon policy and the structure of global trade. World Econ 41(1):194-221

Balistreri EJ, Kaffine DT, Yonezawa H (2019) Optimal environmental border adjustments under the General Agreement on Tariffs and Trade. Environ Resour Econ 74(3):1037-1075

Biden Climate Plan (2020) at https://joebiden.com/climate/. Accessed 10 Aug 2020

Carnegie Endowment for International Peace, "Oil-Climate Index," 2020. https://oci.carnegieendowment.org. Accessed 10 Aug 2020.

Climate Leadership Council, 2019 at https://clcouncil.org/our-plan. Accessed 10 Aug 2020.

COP24, "The Katowice Rulebook - Main Principles of the Document," May 6, 2019. https://cop24.gov. $\mathrm{pl} /$ news/news-details/news/the-katowice-rulebook-main-principles-of-the-document/. Accessed 10 Aug 2020

Copeland BR, Taylor MS (2004) Trade, growth, and the environment. J Econ Lit 42(1):7-71

Cosbey A, Droege S, Fischer C, Munnings C (2019) Developing guidance for implementing border carbon adjustments: lessons, cautions, and research needs from the literature. Rev Environ Econ Policy 13(1):3-22 
European Commission (2019) "The European Green Deal". https://ec.europa.eu/info/sites/info/files/europeangreen-deal-communication_en.pdf. Accessed 10 Aug 2020

Fischer C, Fox AK (2012) Comparing policies to combat emissions leakage: border carbon adjustments versus rebates. J Environ Econ Manag 64(2):199-216

Gray WB, Metcalf GE (2017) Carbon tax competitiveness concerns: assessing a best practices carbon credit. Natl Tax J 70(2):447-468

Hafstead MAC, Williams RC (2018) Unemployment and environmental regulation in general equilibrium. J Public Econ 160:50-65

Helm D, Hepburn C, Ruta G (2012) Trade, climate change, and the political game theory of border carbon adjustments. Oxford review ofeconomic policy 28(2):368-394

Holmes P, Reilly T, Rollo J (2011) Border carbon adjustments and the potential for protectionism. Clim Pol 11(2):883-900

IEA, "Tracking Clean Energy Progress," 2019. https://www.iea.org/topics/tracking-clean-energy-progress. Accessed 10 Aug 2020

Kortum S, Weisbach D (2017) The design of border adjustments for carbon prices. Natl Tax J 70(2):421

McGlade C, Ekins P (2015) The geographical distribution of fossil fuels unused when limiting global warming to $2{ }^{\circ} \mathrm{C}$ Nature 517, 187-190 at https://www.nature.com/articles/nature14016

Mehling MA, van Asselt H, Das K, Droege S (2018) Beat Protectionism and Emissions at a Stroke 322 Nature, 559

Mehling MA, van Asselt H, Das K, Droege S, Verkuijl C (2019) Designing border carbon adjustments for enhanced climate action. American Journal of International Law 113(3):433-481

Nordhaus W (2015) Climate clubs: overcoming free-riding in international climate policy. Am Econ Rev 105(4): $1339-1370$

Oda J, Akimoto K, Tomoda T, Nagashima M, Wada K, Sano F (2012) International comparisons of energy efficiency in power, steel, and cement industries. Energy Policy 44:118-129

Prag A (2020) The climate challenge and trade: would border carbon adjustments accelerate or hinder climate action? Background paper for the 39th round table on sustainable development. OECD Headquarters, Paris

Roman-White S, Rai S, Littlefield J, Cooney G, Skone TJ (2019) Life Cycle Greenhouse Gas Perspective on Exporting Liquefied Natural Gas from the United States: 2019 Update," National Energy Technology Laboratory, Pittsburgh. https://www.energy.gov/sites/prod/files/2019/09/f66/2019\%20NETL\%20LCAGHG\%20Report.pdf. Accessed 10 Aug 2020

von der Leyen U (2019) A Union that strives for more My agenda for Europe Political Guidelines for the Next European Commission 2019-2024

World Bank Group (2019) State and trends of carbon pricing 2019. World Bank, Washington, DC

Publisher's note Springer Nature remains neutral with regard to jurisdictional claims in published maps and institutional affiliations. 